\title{
STUDY ON SERUM MAGNESIUM, CALCIUM AND IRON IN AUTISM SPECTRUM DISORDER (ASD) CHILDREN
}

\author{
SHAHJADI $\mathrm{S}^{1}, \mathrm{KHAN} \mathrm{S}^{2}$, AHMED MU ${ }^{3}, \mathrm{KARIM} \mathrm{M}^{4}$, PARVIN ${ }^{5}$, SIDDIQI UR ${ }^{6}, \mathrm{AFROZ}^{7}$, \\ MAHRUBA SN ${ }^{8}$
}

\begin{abstract}
Background: Autism is a complex neurodevelopmental disorder and one of the major cause of lifelong disability. Magnesium, calcium and iron are important minerals of biological system. Hypomagnesaemia, hypocalcaemia and iron deficiency has been found to be associated with abnormal metabolic functions resulting in autistic spectrum disorder.
\end{abstract}

Hypothesis: Serum magnesium, calcium and iron levels are lower in ASD children than healthy control.

Objective: To measure serum magnesium, calcium and iron in ASDchildren and to compare them with healthy control.

Method: This observational type of analytical study with case-control design was conducted in the Department of Physiology, Bangabandhu Sheikh Mujib Medical University, Shahbag, Dhaka from March 2014-January 2016. For this study, 80 children aged 3-10 years were randomly selected, among which 40 were apparently healthy and 40 were diagnosed as ASD. The study group was selected from the Parents' Forum (Mohakhali DOHS, Dhaka) for ASD children and the control group was selected from some regular schools. $5 \mathrm{ml}$ venous blood was collected from both groups for analysis of fasting serum magnesium, calcium and iron. Fasting magnesium, calcium and iron were estimated in all children by standard laboratory method. Independent sample 't' test and proportion (Z) test were used for statistical analysis. Pvalue ÂO. 05 was accepted as significant.

Result: The mean serum magnesium, calcium and iron were significantly lower (pÂO.OO1) in cases as compared to controls. The frequency of hypomagnesaemia, hypocalcaemia and iron deficiency were significantly higher in early diagnosed ASD children, which was 7 (17.5\%), 22 (55\%) and 5 (12.5\%) out of 40 ASD children respectively. The mean values of all the biochemical variables in normal children were within normal ranges.

Conclusion: The results indicate that hypomagnesaemia, hypocalcaemia and iron deficiency are common in ASD children.

Keywords: Autistic spectrum disorder, magnesium, calcium and iron deficiency.

J Dhaka Med Coll. 2018; 27(2) : 199-204

1. Dr. Shorifa Shahjadi, Associate Professor, Department of Physiology, Bangabandhu Sheikh Mujib Medical University, Dhaka, Bangladesh

2. Dr. Arif Salam Khan, Associate Professor, Department of Surgery, Bangabandhu Sheikh Mujib Medical University, Dhaka, Bangladesh

3. Dr. Mesbah Uddin Ahmed, Professor and Head of the Department, Department of Pediatrics, Gono Shasthaya Somaj Vittik Medical College, Savar, Dhaka, Bangladesh

4. Dr. Mahmuda Karim, Assistant Professor, Department of Physiology, East-West Medical College and Hospital, Dhaka.

5. Dr. Shahana Parvin, Assistant Professor, Department of Physiology, Ibrahim Medical College and Hospital, Dhaka.

6. Dr. Umme Raihan Siddiqi, MD Resident, Department of Physiology, Bangabandhu Sheikh Mujib Medical University (BSMMU), Shahbag, Dhaka.

7. Dr. Sharmin Afroz, MD Resident, Department of Physiology, Bangabandhu Sheikh Mujib Medical University (BSMMU), Shahbag, Dhaka.

8. Dr. Syeda Nusrat Mahruba, MD Resident, Department of Physiology, Bangabandhu Sheikh Mujib Medical University (BSMMU), Shahbag, Dhaka.

Address of correspondence: Dr. Shorifa Shahjadi, Associate Professor, Department of Physiology, Bangabandhu Sheikh Mujib Medical University, Dhaka, Bangladesh. Mobile: 01711560441, E-mail: shahjadi79@gmail.com

Received: 12 May 2018

Revision: 26 August 2018

Accepted: 08 September 2018

https://doi.org/10.3329/jdmc.v27i2.45834 


\section{Introduction:}

Autism spectrum disorder (ASD) is behaviorally defined by an extensive deficits in social interaction, impairment in verbal and nonverbal communication, and stereotyped patterns of interests and activities ${ }^{1}$. According to the American Psychiatric Association, ASD is associated with behavioral, developmental, neuropathological and sensory abnormalities. The word spectrum refers to a wide range of disorders having different domains according to the severity of features. Autismis the most familiar diagnosis among the Autism Spectrum Disorders, which also includes pervasive developmental disorder not otherwise specified and Asperger's disorder 2, 3. ASD is usually diagnosed between the ages of 2 to 10 years of age, with peak prevalence between 5 to 8 years of age ${ }^{4}$.

During the first description by Kanner ${ }^{5}$, ASD was a rare disorder but in last three decades, its prevalence increased several folds. Autism may occur in any race, class and religion in all countries of the world. Now global burden of autism is 7.6 per 1000 population or one in every 132 persons $^{6}$. In Bangladesh the prevalence of ASD is 0.15 to $0.8 \%$. In rural area it is $0.075 \%$ but in Dhaka city it is alarmingly high $3 \%{ }^{7,8}$.

ASD is complicated condition in which along with genetic factor, nutritional and environmental factors play major roles ${ }^{9}$. The core feature of autism might play a role in dietary selectivity that result in less consumption of fruits, dairy products, vegetables, proteins and starches by the autistic group. Several studies informed that there were significantly lower levels of various nutrients in the blood of autistic children such as calcium, magnesium, and iron 9, 10, 11.

Magnesium (Mg), calcium and iron are the most important parts of biological system. Magnesium plays important roles in more than 300 enzyme systems significantly involved in energy production, synthesis of essential molecules and regulation of ion transport across the cell membranes. Bradstreet et al. (2010) reported that about $95 \%$ of autistic children had magnesium deficiency ${ }^{12}$. In addition, Priya and
Geetha observed that serum magnesium significantly lower in autistic children compared to age and sex matched controls, which may leads to anxiety, depression, agitation, irritability, nervousness, and learning disability, impairment of social interaction and memory impairment ${ }^{11}$. Peck and Meltzer reported that magnesium ions exert a depressant effect on neuromuscular transmission of central nervous system ${ }^{13}$. On the other hand, Al Farsi et al. Informed that serum magnesium was higher in autistic children ${ }^{14}$.

Krey and Dolmetsch ${ }^{15}$ reported that calcium is an important mineral which plays an important role in the regulation of synaptic transmission and also in the regulation of neuronal excitability. Magnesium deficiency may leads to increased intracellular calcium. Laumonnier et al. suggested that increased intracellular calcium in ASD children compared to control was due to inactivation of ionized $\mathrm{Ca}^{2+}$-activated $\mathrm{K}^{+}$channel $\left(\mathrm{BK}_{\mathrm{Ca}}\right)$ which lead to neuronal hyperexcitability ${ }^{16}$.

In autism, low plasma $\mathrm{Ca}^{2+}$ and high brain $\mathrm{Ca}^{2+}$ readily leads to oxidative stress as mitochondrial oxygen radical is stimulated by increased intracellular $\mathrm{Ca}^{2+17}, 18$. Calcium plays an important role in the activation of different essential enzymes in energy producing pathways, such as á-ketoglutarate dehydrogenase, isocitrate dehydrogenase and pyruvate dehydrogenase 19,20 .

In a recent study, it was reported that about $33.33 \%$ of ASD children had decreased serum calcium compared to matched controls ${ }^{17}$. Another study reported that calcium was significantly lower in autistic children than in the control group, probably due to nutritional deficiency and exposure to environmental toxins, especially during early development ${ }^{14}$. Another study reported that children with ASD had significantly lower levels of serum calcium 21 . On the other hand, another study reported no significant differences in serum calcium levels in ASD and control group 22.

Iron plays an important role in the development and functioning of brain, especially during the early stages of its development ${ }^{23}$. According to Lozoff et al. iron deficiency early in life may 
cause permanent damage to nervous system development and function, resulting in impaired cognition, diminished learning capacity, attention deficit, and neuromotor dysfunction 24. Iron deficiency affects enzymatic activity, oxygen transport and its cellular utilization, energy utilization, hormonal regulation, muscle function, defense mechanisms, intestinal function and absorption, growth and development. According to Horowitz and Greenamyre numerous proteins in almost all compartments of the human cell mitochondria, cytosol, nucleus, endoplasmic reticula - require iron-sulfur complex and/or heme prosthetic groups to support enzymatic and structural functions such as oxidative phosphorylation (complex I-III), TCA cycle (aconitase), DNA repair and heme synthesis ${ }^{25}$.

Iron deficiency is the most common deficiency disease worldwide. In a study Latif, Heinz and Cook suggested that about $52 \%$ of autistic children were iron deficient, which might cause learning and behavioral impairment ${ }^{26}$. According to Cornish about 29\% of autistic children aged 3.5-9.5 year showed low dietary intake of iron 27 .

In this study, we estimated the serum magnesium, calcium and iron levels of ASD children and healthy control and compared the status of these minerals. Our aim is to create consciousness among parents about the detrimental effects of selectivity in feeding and its resultant mineral deficiencies in ASD children.

\section{Methods:}

40 diagnosed children of autism spectrum disorder with age range 3-10 years were taken for this analytical type of case-control study. 40 age and BMI matched apparently healthy children were taken as control. All subjects were excluded for conditions like, epilepsy, Turner syndrome, Down syndrome and children who take any medicationby history taking. This study was conducted in Department of Physiology of Bangabandhu Sheikh Mujib Medical University (BSMMU), Shahbag, Dhaka. The study group was selected from Parents Forum (DOHS, Mohakhali) for Autism spectrum disorder children and control group was collected from some normal school. After selection of the subjects, thorough information was given to their parents about the objectives and study procedure. Their parents were encouraged for voluntary participation of their children. Their parents were also allowed freedom to withdraw their children from the study even after participation whenever they feel like. When their parents agreed for participation, an informed written consent was taken from them. The parents of subject were requested to attend the Department of physiology ofBSMMU, Dhaka for examination of their children. Detail personal, medical, family, socioeconomic, occupational and dietary history of the children were recorded in a data schedule from their parents. Thorough physical examinations of the subjects were done. Then $5 \mathrm{ml}$ of venous blood was collected from antecubital vein of each subject of both groups for estimation of biochemical variables. After collection of blood samples, serum calcium, magnesium and iron were measured in the laboratory of Biochemistry department, BSMMU. Data were expressed in mean $\pm \mathrm{SE}$ and also in percentage. Statistical analysis was done by SPSS for Windows version 16 . Independent samples ' $t$ ' test were used as the tests of significance. P value $<0.05$ was accepted as significant.

\section{Result:}

This study included 40 ASD children as study group and 40 age and BMI matched healthy children as control group. The characteristics of study group and control group are shown in Table 1.The mean serum magnesium levels were significantly lower in children with ASD compared with the normal cases $[2.03$ (SE $=0.03) \mathrm{mg} / \mathrm{dl}$ and $2.16(\mathrm{SE}=0.02) \mathrm{mg} / \mathrm{dl}$, respectively; $\mathrm{P}<0.01$ ]. The mean serum calcium levels were significantly lower in children with ASD compared with the normal cases $[8.90$ (SE $=0.06) \mathrm{mg} / \mathrm{dl}$ and $9.32(\mathrm{SE}=0.06) \mathrm{mg} / \mathrm{dl}$, respectively; $\mathrm{P}<0.001$ ]; Accordingly, the mean serum iron levels werealso significantly $(P$ $<0.001)$ lower in children with ASD than the normal cases $[71.45(\mathrm{SE}=4.42) \mathrm{ig} / \mathrm{dl}$ and 90.10 $(\mathrm{SE}=2.67) \mathrm{ig} / \mathrm{dl}$, respectively; $\mathrm{P}<0.001]$. Out of 40 early diagnosed ASD children, 
hypomagnesaemia was found in 7 (17.5\%) children,hypocalcaemia in $22(55 \%)$ children and iron deficiency in $5(12.5 \%)$ children respectively which was significantly higher than the healthy control children. Among the healthy control children, only one $(2.5 \%)$ boy had hypocalcemia(Table 2).

\section{Table-I}

Characteristics of the study subjects

\begin{tabular}{lccc}
\hline Parameters & $\begin{array}{c}\text { Study } \\
\text { group }\end{array}$ & $\begin{array}{c}\text { Control } \\
\text { group }\end{array}$ & $\begin{array}{c}\mathrm{P} \\
\text { value }\end{array}$ \\
& $\mathrm{n}=40$ & $\mathrm{n}=40$ & \\
\hline Serum Magnesium & $2.03 \pm 0.02$ & $2.14 \pm 0.02$ & $<0.01$ \\
$(\mathrm{mg} / \mathrm{dl})$ & $(1.7-2.5)$ & $(1.9-2.6)$ & \\
Serum Calcium & $8.90 \pm 0.06$ & $9.40 \pm 0.07$ & $<0.001$ \\
$(\mathrm{mg} / \mathrm{dl})$ & $(7.2-9.6)$ & $(8.2-10.4)$ & \\
Serum Iron $(\mu \mathrm{g} / \mathrm{dl})$ & $71.45 \pm 4.42$ & $90.97 \pm 3.01<0.001$
\end{tabular}

$$
(19-124) \quad(58-138)
$$

Data are expressed as mean \pm SE. For statistical analysis, independent student' $t$ ' test was performed for comparison between study (autism spectrum disorder children) and control (healthy children) group. Figures in parentheses indicate ranges. $\mathrm{P}<0.05$ considered as significant, $\mathrm{n}=$ number of subject in each group.

\section{Table-II}

Distribution of hypomagnesaemia, hypocalcaemia and iron deficiency in ASD children of 3-10 years.

\begin{tabular}{lcc}
\hline Characteristics & Study group Control group \\
& $\mathrm{n}=40$ & $\mathrm{n}=40$ \\
\hline Hypomagnesaemia & $7(17.5 \%)$ & $0(0 \%)$ \\
Hypocalcaemia & $22(55 \%)$ & $1(2.5 \%)$ \\
Iron deficiency & $5(12.5 \%)$ & $0(0 \%)$ \\
\hline
\end{tabular}

Data are expressed in number (percentage)

The lower limit of normal level for serum magnesium was $1.9 \mathrm{mg} / \mathrm{dl}$, for serum calcium was $9 \mathrm{mg} / \mathrm{dl}$ and for serum iron was $30 \mathrm{ig} / \mathrm{dl}$.

\section{Discussion:}

The present study was undertaken to observe some biochemical variables in children with autistic spectrum disorder in order to evaluate the alterations in nutritional deficiency. Serum nutritional deficiency were assessed by estimating serum magnesium, calcium and iron levels. All these variables were also studied in apparently healthy age, height, weight and BMI matched children for comparison. In this study, our data indicated a significant decrement in the serum levels of all the variables in ASD children. Whereas mean values of all the biochemical variables of normal children were within physiological limits and were almost similar to those reported by different investigators $28,29,30,31,14,32,18,21,33,12$, ${ }^{34}$.Both the groups were comparable, as there were no significant differences in the confounding variables such as age, height,weight and BMI between the two groups. The mean values of serum magnesium and calcium were below the lower limit of normal range, whereas those of total iron were within the normal range.

In our present study, asignificantly lower serum magnesiumlevel was found in the study group than those of control group. The observed decrease in serum magnesium is in agreement with many previous findings by $34,12,22$. In addition, serum magnesium level was found abnormally low in $17.5 \%$ of children of study group whereas none of them in control group had abnormally low serum magnesium levels. Similarly, Kozielec and Hermelin observed that $33.6 \%$ of autistic children had magnesium deficiency ${ }^{35}$.

This study also showed that serum calcium levels were significantly lower in the study group than in the control group. These findings are consistant with the findings that were observed by El-Ansary et al., Al-Farsi et al., Yasuda et al., Meguid et al. and Sun et al. 18, 14, 36, 21, 37 . Surprisingly, $55 \%$ of children of the study groupwere found abnormally low serum calcium levels. Whereas only $2.5 \%$ of children of the control group had serum calcium levels below the lower limit of normal which was may be due to nutritional deficiency and or vitamin $\mathrm{D}$ deficiency due to inadequate exposure to sun light. In contrary to this finding, Yasuda et al.observed that, only $5.8 \%$ of autistic children had calcium deficiency ${ }^{36}$. 
Decreased levels of serum iron was also observed in this study. Serum iron was significantly lower in the study group than those of control group. Almost similar findings were observed by Cornish, Latif, Heinz and Cook, Bilgic et al. and Konofal et al. ${ }^{27}, 26,33$.In addition, serum iron level was found abnormally low in $12.5 \%$ of children of study group.But none of them in control group had abnormally low serum magnesium levels. Similar findings were observed in $84 \%$ of ASD children by Konofal et al. in $29 \%$ by Cornish); in $52 \%$ by Latif, Heinz and Cook and in $32.3 \%$ by Bilgic et al. $27,26,33$.

\section{Conclusion:}

The results indicate that hypomagnesaemia, hypocalcaemia and iron deficiency are common in ASD children.

\section{References:}

1. Manzi B, Loizzo AL, Giana G \& Curatolo P. Autism and metabolic diseases.Journal of Neurology.2008; 23(3): 307-14.

2. American Psychiatric Association. Diagnostic and Statistical Manual of Mental Disorder, Fifth edition. Washington, DC. APA. 2013; 49:168.

3. Aneja A \& Tierney E. Autism: the role of cholesterol in treatment.International Review of Psychiatry. 2008; 20(2): 165-70.

4. Allsopp MY, Rice C, Karapurkar T, Doernberg N, Boyle C \& Murphy C. Prevalence of autism in a US metropolitan area.The Journal of the American Medical Association. 2003; 289 (1): 49-55.

5. Kanner L. Autistic disturbance of affective contact. Nervous Child. 1943; 2: 217-50.

6. Baxter1 AJ, Brugha TS, Erskine HE, Scheurer RW, Vos T, Scott JG. The epidemiology and global burden of autism spectrum disorders. Psychological Medicine. 2015; 45: 601-13. doi:10.1017/ S003329171400172X

7. Hossain MD, Ahmed HU, Uddin MMJ, Chowdhury WA, Iqbal MS et al. Autism Spectrum disorders (ASD) in South Asia: a systematic review. BMC Psychiatry. 2017; 17:281. DOI 10.1186/s12888-017-1440-x

8. Akhter S, Hussain AHME, Shefa J et al. Prevalence of Autism Spectrum Disorder (ASD) among the children aged 18-36 months in a rural community of Bangladesh: A cross sectional study [version 1; referees: 1 approved, 1 approved with reservations]. F1000Research. 2018; 7:424. doi:10.12688/ f1000research.13563.1
9. Luke, T and Patel, K Nutritional and environmental approaches to preventing and treating Autism and Attention Deficit Hyperactivity Disorder (ADHD): A Review.The Journal of Alternative and Complementary Medicine2008; 14(1): 89-85.

10. El-Ansary, AK, Ben Bacha, AG \& Al-Ayadhi, LY. Proinflammatory and proapoptotic markers in relation to mono and di-cations in plasma of autistic patients from Saudi Arabia. Journal of Neuroinflammation. 2011; 8: 142.

11. Priya, MDL \&Geetha, A. Level of trace elements (copper, zinc, magnesium and selenium) and toxic elements (lead and mercury) in the hair and nail of children with autism. Biological Trace Element Research. 2010; 142 (2):148-158.

12. Bradstreet JJ, Smith S, Baral M, Rossignol DA. Biomarker-guided interventions of clinically relevant conditions associated with autism spectrum disorders and attention deficit hyperactivity disorder. Alternative Medicine Review: a Journal of Clinical Therapeutic. 2010; 15(1): 15-32.

13. Peck $\mathrm{CH} \&$ Meltzer SJ. Anesthesia in human beings by intravenous injection of magnesium sulphate. The Journal of the American Medical Association. 1916; 67 (16):1131-3.

14. Al-Farsi YM, Waly MI, Al-Sharbati MM, Al-Shafaee MA, Al-Farsi OA, Al-Khaduri et al. Levels of Heavy Metals and Essential Minerals in Hair Samples of Children with Autism in Oman: A Case-Control Study. Biol Trace Elem Re. 2012; 151: 181-6. DOI $10.1007 / \mathrm{s} 12011-012-9553-Z$

15. Krey JF and Dolmetsch RE. Molecular mechanism of autism: a possible role for $\mathrm{Ca}^{2+}$ signaling. Current Opinion in Neurobiology. 2007; 17 (1):112-9.

16. Laumonnier F, Roger S, Guérin P, Molinari F, M'rad $\mathrm{R}$, Cahard D et al.Association of a functional deficit of the BKCa channel, a synaptic regulator of neuronal excitability, with autism and mental retardation. The American Journal of Psychiatry. 2006; 163 (9):16229.

17. El-Ansary, AK, Ben Bacha, AG \& Al-Ayadhi, LY. Proinflammatory and proapoptotic markers in relation to mono and di-cations in plasma of autistic patients from Saudi Arabia. Journal of Neuroinflammation. 2011; 8: 142.

18. El-Ansary AK, Al-Daihan S, Al-bass A and Al- Ayadhi L. Measurment of selected ions related to oxidative stress and energy metabolism in Saudi autistic children. Journal of Clinical Biochemistry. 2010; 43: 63-7.

19. Castaldo P, Cataldi M, Magi S, Larccia V, Arcangali S \& Amoroso S. Role of the mitochondrial sodium/ calcium exchanger in neuronal physiology and in the pathogenesis of neurological diseases.Progress in Neurobiology. 2009; 87(1): 58-79. 
20. Benedicte O, Dolores DP andMounia C. Mitochondrial calcium signaling: Role in oxidative phosphorylation diseases. K Clark (ed), Bioenergetics. 2012; InTech, Rijeka, Croatia.

21. Meguid NA, Hashish AF, Anwar M, and Sidhom G. Reduced Serum Levels of 25-Hydroxy and 1,25Dihydroxy Vitamin D in Egyptian Children with Autism. The journal of alternative and complementary medicine.2010; 16 (6):641-45. DOI: 10.1089/ acm.2009.0349

22. Adams JB, Audhya T, McDonough-Means S, Rubin RA, Quig D, Geis E et al. Nutritional and metabolic status of children with autism vs. neurotypical children, and the association with autism severity. Nutrition \& Metabolism. 2011; 8:34.

23. Oski FA.Iron deficiency in infancy and childhood. The New England Journal of Medicine. 1993; 329(3):19093.

24. Lozoff, B Jimenez E and Wolf AW. Long-term developmental outcome of infants with iron deficiency. The New England Journal of Medicine. 1991; 325(10): 687-69

25. Horowitz MP and Greenamyre JT. Mitochondrial iron metabolism and its role in neurodegenaration. Journal of Alzheimer's disease.2010;20: 551-68.

26. Latif A, Heinz $P$ and Cook R. Iron deficiency in autism and Asperger syndrome. Autism. 2002; 6 (1):103-14.

27. Cornish E. A balanced approach towards healthy eating in autism. Journal of Human Nutrition and Dietetics. 1998; 11 (6): 501-50

28. Kim E-K, Neggers YH, Shin C-S, Kim E \& Kim ME.Alterations in lipid profile of autistic boys: a case control study. Nutrition Research. 2010; 30 (4):25560 .

29. Dziobek I, Gold SM, Wolf OT \& Convit A. Hypercholesterolemia in Aspergersyndrome:
Independent from lifestyle, obsessive- compulsive behavior and social anxity. Psychiatric Research. 2007; 149:321-4.

30. Wiest MM, German JB, Harvey DJ, Watkins SM and Picciotto IH. Plasma fatty acid profile in autism: A case control study. Prostaglandins, Leukotrienes and Essential Fatty Acids. 2009;8: 221-7.

31. Kurup RK \& Kurup PA. A hypothalamic digoxinmediated model for autism. International Journal of Neuroscience. 2003; 113(1): 1537-59.

32. Herndon AC, DiGuiseppi C, Johnson SL, Leiferman $\mathrm{J} \&$ Reynolds A. Does nutritional intake differ between children with autism spectrum disorders and children with typical development? Journal of Autism Developmental Disorders. 2009; 39(2):21222.

33. Bilgic A, Gurkan K, Turkoglu S, Akca O F, Kilic B \& Uslu R. Iron deficiency in preschool children with autistic spectrum disorder. Research in Autism Spectrum Disorders. 2010; 4 (4):639-44.

34. Strambi M, Longini M, Hayek J, Berni S, Macucci F, Scalacci E \& Vezzosi P. Magnesium profile in autism. Biological Trace Element Research. 2005; 109 (2): 97-104.

35. Kozielec T, Hermelin BS. Assessment of magnesium levels in children with attention deficit hyperactivity disorder (ADHD). Magnes Res. 1997 Jun; 10(2): 1438.

36. Yasuda H, Kobayashi M, Yasuda Y \& Tsutsi T. Estimation of autistic children by metallomics analysis. Scientific Report. 2013; 3: 1199.

37. Sun C, Xia W, Zhao Y, Li N, Zhao D and Wu, L. Nutritional status survey of children with autism and typically developing children aged 4-6 years in Heilongjiang Province, China,J Nutr Sci. 2013; 2: e16, 1-8. 